Available online at_www.iponlinejournal.com

\title{
Solid acid catalyst for isobutyl propionate production from solid waste
}

\section{Anita Bhatia ${ }^{*}$, Sarishti Sharma ${ }^{2}$}

${ }^{\mathbf{1}}$ Assistant Professor, ${ }^{\mathbf{2}}$ Research Scholar, ${ }^{\mathbf{1}}$ Dept. of Chemistry, ${ }^{\mathbf{1}}$ S.S. Jain Subodh P.G. Autonomous College, University of Rajasthan, Jaipur, India

\begin{abstract}
This paper presents a study of the isobutanol based esterification of propionic acid with the synthesized solid acid catalyst (NAFA) at different temperature and reaction time. An efficient nano crystalline solid acid catalyst (NAFA) with crystallite size of $14 \mathrm{~nm}$ has been synthesized by F-type fly ash $\left(\mathrm{SiO}_{2}\right.$ and $\left.\mathrm{Al}_{2} \mathrm{O}_{3}>70 \%\right)$ by chemical activation using concentrated $\mathrm{HNO}_{3}$ at $110^{\circ} \mathrm{C}$. The Catalyst was characterized by XRD, FT-IR, and SEM techniques. Fly ash generated catalytic material has shown sufficient catalytic activity for esterification of propionic acid and isobutyl alcohol to give isobutyl propionate, which is widely used in food and beverage industries as a rum flavor. The catalyst was completely recyclable without significant loss in activity up to four reaction cycles, which confers its stability during reaction. The work reports an innovative use of solid waste fly ash as an effective solid acid catalyst.
\end{abstract}

Keywords: Fly ash, Chemical activation, Acid treatment, Esterification, Eco-friendly and Isobutyl propionate (RUM).

\section{Introduction}

Esterification is the most widely used reaction in the organic chemical synthesizing industries because it presents a lot of applications ranging from natural product synthesis at lab scale to industrial scale production. This reaction is frequently encountered in the organic process industries due to its diverse applications of esters in a variety of industries such as pharmaceuticals intermediates, fine chemical, fragrance and flavour chemicals, plasticizers, solvents, food etc. ${ }^{1}$ Esters cover a very wide category ranging from aliphatic to aromatic with various substitutions and multifunctional groups. ${ }^{2}$

Isobutyl propionate is food spices. Mainly for the preparation of rum, strawberries and other fruits flavor. It can be synthesized by esterification of propionic acid with isobutanol using acid catalyst. Commercially this reaction was carried out using various homogeneous acid catalysts such as $\mathrm{H}_{2} \mathrm{SO}_{4}$, $\mathrm{HF}, \mathrm{H}_{3} \mathrm{PO}_{4}$ and other mineral acids which are environmentally hazardous, corrosive, nonreusable, poring several disadvantages in industrial processes, produce neutralization waste and also include wasting large amount of catalyst etc. . $^{3-7}$

The esterification reaction have been widely investigated using several solid acids such as, nanosized silicotungstic acid (STA) supported on zirconia embedded inside the various mesoporous silicas such as SBA-15, MCM-41 and MCM-48, ${ }^{8,9}$ Amberlyst$36,{ }^{10}$ cation-exchange resin catalyst, Purolite CT$175,{ }^{11} \mathrm{ZrO}_{2}$ supported tungstophosphoric (TPA) ${ }^{12}$ and molybdophosphoric (MPA). ${ }^{13}$

The present research paper elaborates an innovative support material Fly ash is selected which is a solid waste generated in power plants and being rich in silica is used in synthesizing NAFA Catalyst having wide applications in production of Isobutyl Propionate (RUM), used in food and beverage industries. This catalyst may also be explored for other esterification products to be used in synthesis of food preservatives and pharmaceutical.

\footnotetext{
*Corresponding Author: Anita Bhatia, Dept. of Chemistry, S.S. Jain Subodh P.G. Autonomous College, University of Rajasthan, Jaipur, India

Email: anisharma00@gmail.com

http://doi.org/10.18231/j.ijpca.2019.013
} 


\section{Experimental Apparatus and Methods Raw material and reagents}

$\mathrm{HNO}_{3}$ (98\%), Isobutyl alcohol (99\%) was purchased from S. D. Fine Chem. Ltd.and Propanoic acid (99\%) from Merck AG. The coal fly ash (Class F-type) used as solid support was collected from Tata Thermal Power Plant, Jamshedpur.

\section{Apparatus and catalyst synthesis procedure}

As received fly ash was thermally activated at $900^{\circ} \mathrm{C}$ for $4 \mathrm{~h}$ to remove $\mathrm{C}, \mathrm{S}$, and other Impurities. Chemical activation was carried out by treating fly ash with concentrated nitric acid. The mixture was heated at $110^{\circ} \mathrm{C}$ under stirring and aged for few days maintaining the temperature. After ageing, the dark pulp obtained was washed with distilled water to remove leached compounds. The pulp thus obtained was dried at $110^{\circ} \mathrm{C}$ for overnight. ${ }^{14}$ The chemically activated material was thermally stabilized by calcinations at appropriate temperature for $4 \mathrm{~h}$ in static conditions. The scheme for the preparation of NAFA catalyst is given in Scheme

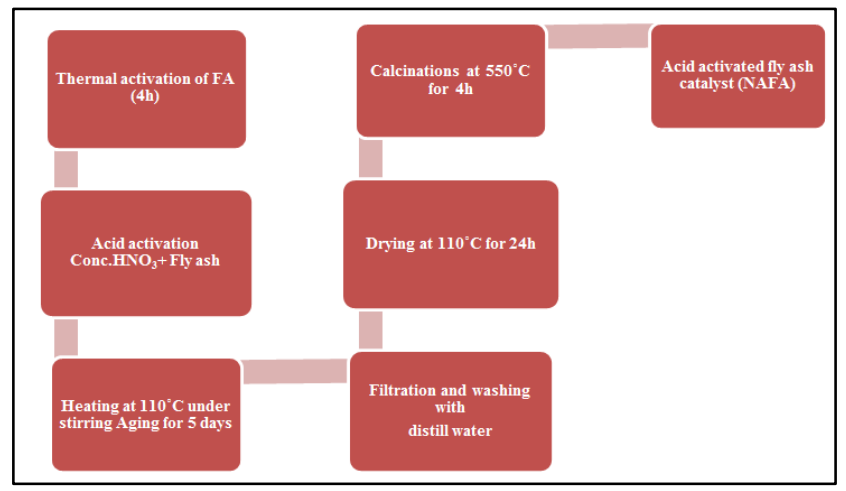

Scheme 1.1: Synthesis of acid activated fly ash catalyst (NAFA) from fly ash.

\section{Catalyst characterization techniques}

The silica content of the fly ash samples after activations were analyzed by X-ray fluorescence spectrometer (Philips PW1606). The BET surface area was measured by $\mathrm{N}_{2}$ adsorption-desorption isotherm study at liquid nitrogen temperature $(77 \mathrm{~K})$ using Quantachrome NOVA 1000e surface area analyzer.

FTIR spectra of the materials were recorded in the range $550-4000 \mathrm{~cm}-1$ with a resolution of $4 \mathrm{~cm}-1$ using FTIR Tensor 27 Brucker with DR (Diffuse
Reflectance) accessory. The detailed imaging information about the morphology and surface texture was provided by SEM-EDX (Philips XL30 ESEM TMP). The Bronsted and Lewis acidity of the catalysts were measured by pyridine adsorbed FT-IR (Tensor27, Bruker, Germany, with DRS. The detailed imaging information about the morphology and surface texture of the sample was provided by SEM-EDAX (Philips XL30 ESEM TMP).

\section{Catalytic activity of NAFA}

The catalytic performance of the NAFA catalyst was evaluated by esterification of propionic acid with isobutanol (Scheme 1.2) to give Isobutyl Propionate (RUM) as test reaction in a liquid phase batch reactor.

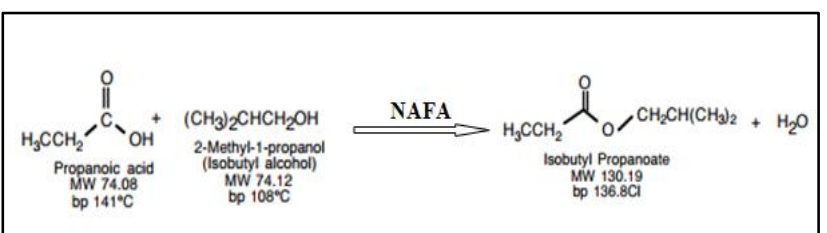

Scheme 1.2: Esterification of propionic acid with isobutanol over NAFA catalyst.

\section{Esterification of propionic acid with isobutanol}

The esterification of propionic acid with isobutanol using NAFA catalyst was carried out in a liquid phase batch reactor. In the procedure, isobutanol and propionic acid (molar ratio of isobutanol with propionic acid $=1: 2$ ) were taken in a $100 \mathrm{ml}$ round bottom flask, equipped with magnetic stirrer and condenser, immersed in a constant temperature oil bath. The catalyst activated at $550^{\circ} \mathrm{C}$ for $2 \mathrm{~h}$ prior to the reaction in static air, was added in the reaction mixture. The reaction mixture was heated at required reaction temperature ranging from $110^{\circ} \mathrm{C}$ to $130^{\circ} \mathrm{C}$ for difference time from $1 \mathrm{~h}$ to $2 \mathrm{~h}$. Process parameters such as reaction time, temperature, molar ratio of the reactant, weight of the catalyst and acid to alcohol molar ratio were optimized to achieve maximum conversion

After a stipulated time the reaction mixture was cooled to room temperature, acetone was added to dissolve the unreached salicylic acid in the reaction mixture and filtered to separate out the catalyst. The product obtained was analyzed by melting point 
measurement, FT-IR and Gas Chromatography (Dani Master GC) having a flame ionization detector and HP-5 capillary column of $30 \mathrm{~m}$ length and $0.25 \mathrm{~mm}$ diameter, programmed oven temperature of $50-280^{\circ} \mathrm{C}$ and $\mathrm{N}_{2}(1.5 \mathrm{ml} / \mathrm{min})$ as a carrier gas. ${ }^{15}$

Table:

\begin{tabular}{|c|c|c|c|c|c|c|c|}
\hline S. No. & Substrate & $\begin{array}{l}\text { Mole } \\
\text { ratio }\end{array}$ & $\begin{array}{l}\text { Product } \\
\text { (esters) }\end{array}$ & $\begin{array}{c}\text { Catalyst } \\
\text { amount (g) }\end{array}$ & $\begin{array}{l}\text { Reaction } \\
\text { Time (h) }\end{array}$ & $\begin{array}{c}\text { Temperature } \\
\left({ }^{\circ} \mathrm{C}\right)\end{array}$ & $\begin{array}{c}\% \\
\text { Yield }\end{array}$ \\
\hline \multirow[t]{7}{*}{1.} & $\begin{array}{l}\text { Isobutanol + } \\
\text { propionic acid }\end{array}$ & $1: 1$ & $\begin{array}{l}\text { Isobutyl propionate } \\
\text { (RUM) }\end{array}$ & 0.2 & 2 & $110^{\circ} \mathrm{C}$ & 68 \\
\hline & & $1: 1$ & & 0.2 & 2 & $120^{\circ} \mathrm{C}$ & 78 \\
\hline & & $1: 1$ & & 0.2 & 2 & $130^{\circ} \mathrm{C}$ & 88 \\
\hline & & $1: 1.5$ & & 0.2 & 2 & $120^{\circ} \mathrm{C}$ & 90 \\
\hline & $\begin{array}{l}\text { Optimized } \\
\text { condition }\end{array}$ & $1: 2$ & & 0.2 & 2 & $120^{\circ} \mathrm{C}$ & 98 \\
\hline & & $1.5: 1$ & & 0.2 & 2 & $120^{\circ} \mathrm{C}$ & 82 \\
\hline & & $1: 1.5$ & & 0.2 & 2 & $130^{\circ} \mathrm{C}$ & 94 \\
\hline
\end{tabular}

\section{Catalyst Regeneration}

After completion of the reaction, catalyst was filtered and washed thoroughly with acetone and dried in an oven at $110^{\circ} \mathrm{C}$ for $12 \mathrm{~h}$ followed by activation at $500^{\circ} \mathrm{C}$ for $2 \mathrm{~h}$ in static condition prior to the use in next reaction cycle under the similar reaction conditions.

\section{Result and Discussion}

\section{Characterization of fly ash catalysts}

The chemical composition of FA and NAFA catalyst are summarized in Table 1.1 and 1.2, which shows that after chemical activation the silica content in NAFA catalyst is greatly increased (61.9\% to $84 \%)$. The BET surface area of NAFA catalyst $\left(5.8 \mathrm{~m}^{2} / \mathrm{g}\right)$ is also increased as compared to FA $\left(0.97 \mathrm{~m}^{2} / \mathrm{g}\right)$ while particle diameter is reduced $(\mathrm{FA}=37.7 \mu \mathrm{m}$ and NAFA $=3.71 \mu \mathrm{m})$ during chemical activation. ${ }^{16,17}$ The increase in silica content after activation shows the loss of other components during the chemical activation with higher concentration of $\mathrm{HNO}_{3}{ }^{18}$

Table 1.1: Chemical composition of fly ash samples before and after chemical activation.

\begin{tabular}{|c|c|c|c|c|c|c|c|c|c|c|}
\hline Sample & $\begin{array}{c}\mathbf{S i O}_{2} \\
(\mathbf{w t} \%)\end{array}$ & $\begin{array}{c}\mathbf{A l}_{2} \mathbf{O}_{\mathbf{3}} \\
(\mathbf{w t} \%)\end{array}$ & $\begin{array}{c}\mathbf{F e}_{2} \mathbf{O}_{3} \\
(\mathbf{w t} \%)\end{array}$ & $\begin{array}{c}\mathbf{C a O} \\
(\mathbf{w t} \%)\end{array}$ & $\begin{array}{c}\mathbf{M g O} \\
(\mathbf{w t} \%)\end{array}$ & $\begin{array}{c}\mathbf{T i O}_{2} \\
(\mathbf{w t} \%)\end{array}$ & $\begin{array}{c}\mathbf{N a}_{2} \mathbf{O} \\
(\mathbf{w t} \%)\end{array}$ & $\begin{array}{c}\mathbf{K}_{2} \mathbf{O} \\
(\mathbf{w t} \%)\end{array}$ & $\begin{array}{c}\text { Other } \\
\text { element }\end{array}$ & LOI \\
\hline FA & 61.9 & 29.7 & 2.65 & 0.46 & 0.36 & 1.33 & 0.14 & 0.79 & 2.67 & 2.6 \\
\hline NAFA & 84 & 11.7 & 1.60 & 0.22 & 0.18 & 0.87 & 0.06 & 0.39 & 0.98 & 1.45 \\
\hline
\end{tabular}

Table 1.2: Physico-chemical properties of FA and NAFA catalyst

\begin{tabular}{|c|c|c|c|c|}
\hline Catalyst & $\begin{array}{c}\text { Silica } \\
(\mathbf{w t} \%)\end{array}$ & $\begin{array}{c}\text { Crystallite size } \\
(\mathbf{n m})\end{array}$ & $\begin{array}{c}\text { BET surface } \\
\text { area }\left(\mathbf{m}^{\mathbf{2}} \mathbf{/ g}\right)\end{array}$ & $\begin{array}{c}\text { Particle } \\
\text { diameter }(\boldsymbol{\mu m})\end{array}$ \\
\hline FA & 61.9 & 33 & 0.97 & 37.7 \\
\hline NAFA & 84 & 14 & 5.80 & 3.71 \\
\hline
\end{tabular}


Powder X-ray diffraction patterns of FA (Fig. 1.1A) and NAFA catalyst (Fig. 1.1B) show the existence of crystalline phases (mullite, quartz, hematite and small amounts of magnetite) and amorphous phases. ${ }^{19,20}$ Quartz and aluminosilacets are found as crystals and as amorphous particles while iron rich particles exist as mixed iron oxide/aluminosilicate particles. X-ray differaction pattern of NAFA (Fig. 1.1B) shows, that the crystallinity is decreased due to removal of most of the crystalline components present in FA, thus increasing the amorphous nature. ${ }^{21}$ The characteristic peaks of quartz in the NAFA are more concentrated in these fractions and indicate increment in $\mathrm{SiO}_{2}$ concentration. The increase in quartz content leads to decrease in particle size distribution of fly ash.

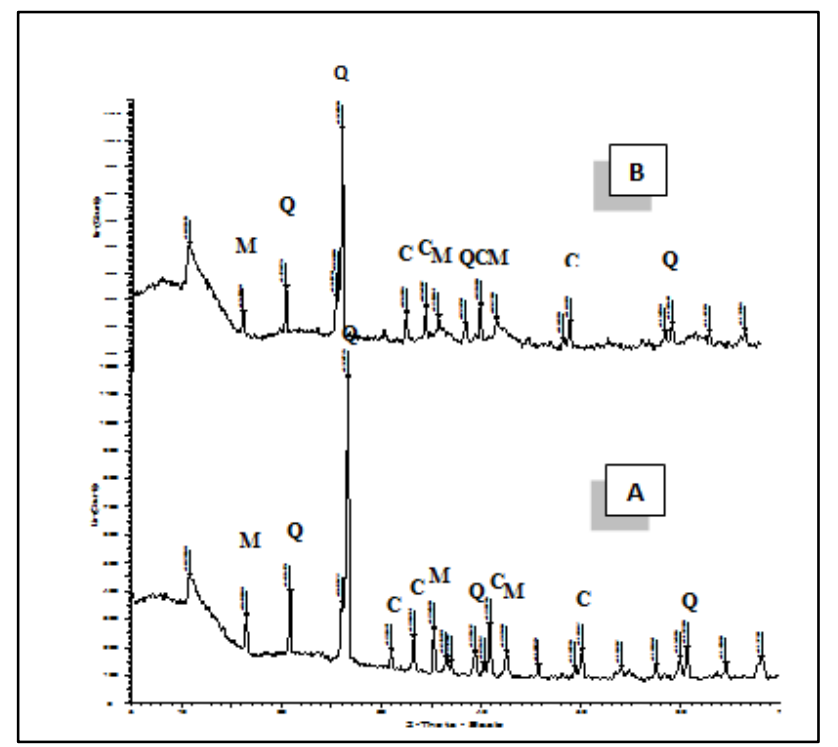

Fig. 1.1: X-ray diffraction pattern of A.) FA and B.) NAFA Catalyst

( $\mathrm{Q}=$ Quartz, $\mathrm{C}=$ Calcite, $\mathrm{M}=$ Mullite $)$

The FT-IR spectrum of FA (Fig. 1.2 (i) shows band at $3632 \mathrm{~cm}^{-1}$ which is attributed to surface $-\mathrm{OH}$ groups of $\mathrm{Si}-\mathrm{OH}$ and adsorbed water molecule on the surface. A peak at $1650 \mathrm{~cm}^{-1}$ in the spectra of both the samples is attributed to bending mode of water molecule. A band at $1100 \mathrm{~cm}^{-1}$ is corresponding to $\mathrm{Si}-\mathrm{O}-\mathrm{Si}$ asymmetric stretching which is shifted to $1155 \mathrm{~cm}^{-1}$ after chemical activation (Fig. 1.2(ii). After chemical activation, the increase in silica content results in increase in the surface hydroxyl groups showing the broad and intense peak for hydroxyl groups at $3493.24 \mathrm{~cm}^{-1}{ }^{22}$
The increased amorphous silica is characterized in NAFA catalyst by an intense band in the range 1000$1300 \mathrm{~cm}^{-1}$, corresponding to the valence vibration of the silicate oxygen skeleton. The FT-IR spectrum of NAFA, after chemical activation (Fig. 1.2(ii), shows a significant increase in peak intensity of the band for $\mathrm{OH}$ group. FT-IR studies clearly showed changes in the intensity of IR peaks corresponding to $\mathrm{Si}-\mathrm{O}-\mathrm{Si}$ bending $\left(572 \mathrm{~cm}^{-1}\right)$, Si-O-Si symmetric stretching (633 $\left.\mathrm{cm}^{-1}\right)$ and $\mathrm{T}-\mathrm{O}-\mathrm{Si}(\mathrm{T}=\mathrm{Si}, \mathrm{Al})$ asymmetric stretching $\left(1155 \mathrm{~cm}^{-1}\right)$. The peak at $1612 \mathrm{~cm}^{-1}$ may be attributed to the $\mathrm{N}=\mathrm{O}$ stretching band in FA treated with $\mathrm{HNO}_{3}$ (Fig. 1.2(ii). ${ }^{23}$

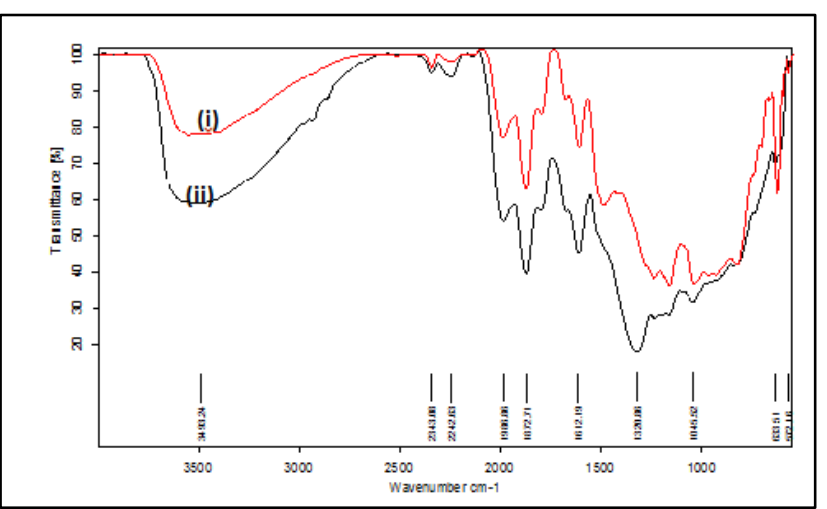

Fig. 1.2: FT-IR spectra of (i) FA and (ii) NAFA catalyst.

In view of learning more about the development of the type of surface acidity after chemical activation of fly ash by acid pyridine-IR studies are performed and the FT-IR spectra obtain after pyridine adsorption of dehydrated acid activated fly ash samples are presented in Fig. 1.3 at the magnified range of 1600$1450 \mathrm{~cm}^{-1}$. The peaks observed at $1540-1552 \mathrm{~cm}^{-1}$ and $1480-1492 \mathrm{~cm}^{-1}$ for acid activated fly ash samples confirm the presence of sufficient Brønsted acidity on the surface due to formation of co-ordinated pyridine and hydrogen bonded pyridine respectively with surface silanol groups. ${ }^{24,25}$ The intensity of absorption band at $1552 \mathrm{~cm}^{-1}$ assign exclusively for Brønsted acidity in NAFA catalyst due to intense hydrogen bonding at higher concentration of $\mathrm{HNO}_{3}$. 


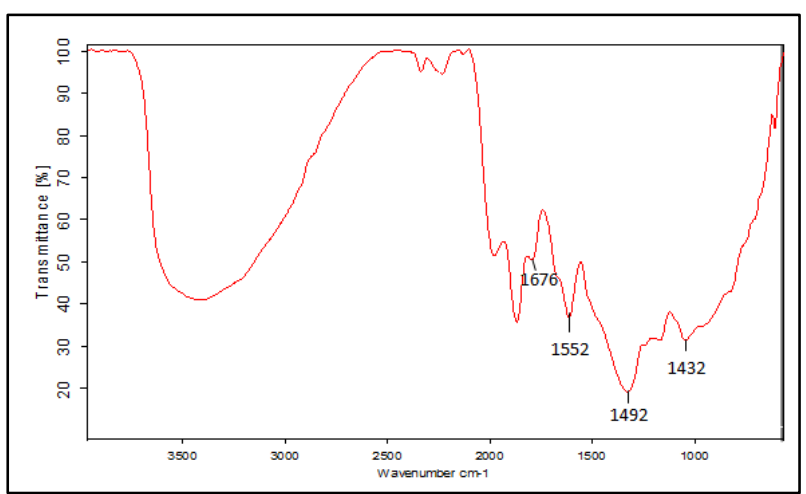

Fig. 1.3: FT-IR spectra of pyridine-adsorbed NAFA catalyst.

SEM micrograph of FA (Fig. 1.4A) indicates that the most of the particles present in the fly ash are spherical in shape with a relatively smooth surface grain consisting of quartz and also shows clusters of iron particles formed due to partial decomposition of pyrite and with dark quartz inclusions. ${ }^{26}$ After chemical activation in NAFA the crystalline and spherical particles break down into amorphous ones and get agglomerated as shown in Fig. 1.4B. The absence of spherical particles in treated fly ash (as evident from the SEM) indicates high conversion of fly ash to amorphous material. The increased surface roughness after acid leaching is clearly indicated in NAFA catalyst in Fig. 1.4B.

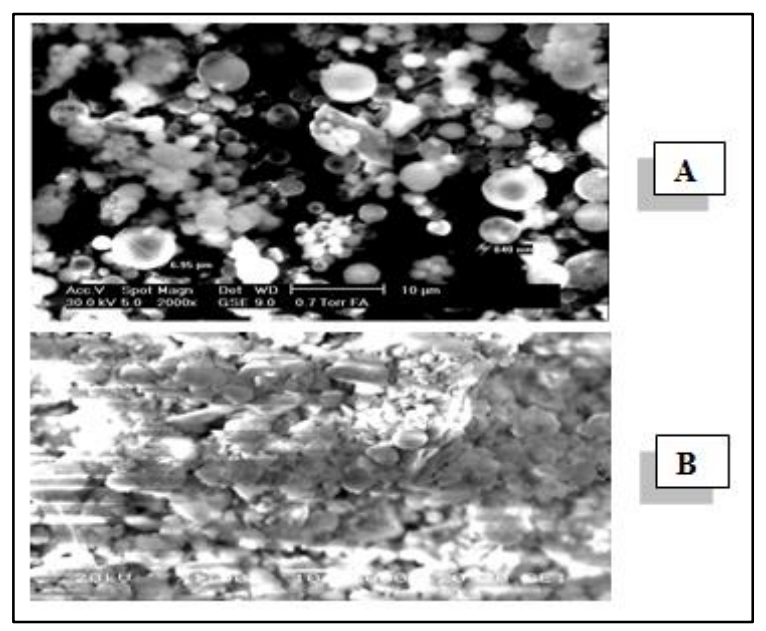

Fig. 1.4: SEM micrographs of (A) FA and (B) NAFA catalyst.

\section{Catalytic performance of NAFA Catalyst}

In order to understand the effect of activation of fly ash on surface acidity and therefore, the catalytic activity, the catalytic performance of NAFA was evaluated for esterification reaction in single step, solvent free condition.

The catalyst NAFA was found highly active for esterification of propionic acid with isobutanol giving high yield (94\%) of isobutyl propionate (RUM) after 2h. Results given in Table 1.3 show that FA did not possess any catalytic activity for studied reaction, while NAFA catalyst showed maximum activity.

Table 1.3: Catalytic activity of FA and NAFA catalyst for esterificatio reaction

\begin{tabular}{|c|c|c|}
\hline Catalyst & \% Conversion & \% Yield \\
\hline FA & Nil & Nil \\
\hline NAFA & 84 & 94 \\
\hline
\end{tabular}

\section{Conclusion}

This article deals with application of fly ash supported nano crystalline solid acid catalysts (nafa) with crystallite size of $14 \mathrm{~nm}$, for esterification of propionic acid and isobutanol. The process adopted for their preparation, their textural properties, thermal treatment, reuse, and leaching aspect have been discussed. The catalyst has reduced particle diameter $3.71 \mu \mathrm{m}$ quite less than that of FA $(37.7 \mu \mathrm{m})$ (Table 1.2). The surface area of the catalyst is $5.80 \mathrm{~m}^{2} / \mathrm{g}$. The chemical activation of fly ash by acid leaching resulted in increased amorphous silica content up to $84 \%$ and thus increased surface hydroxyl groups responsible for surface acidity.

The excellent acidic properties of synthesized catalyst have been evaluated by means of esterification of propionic acid with isobutanol to give high yield 94\% of desired product isobutyl propionate (rum), which has found wide applications as in beverage industries as a rum flavor.

The catalyst was easily separated by simple filtration, regenerated and reused several times with equal efficiency, thus produces no waste and makes the process economic.

\section{Acknowledgement}

The authors are thankful to Dr. D.D. Phase and Er. V.K. Ahiray for SEM-EDX analysis and Mukul Gupta for XRD conducted at UGC DAE-CSR Lab Indore. 
XRF analysis was conducted at Punjab University, Chandigarh.

\section{Source of Funding}

The financial support was provided by Fly Ash Mission, Department of Science and Technology, New Delhi, India.

\section{Conflict of Interest}

None.

\section{References}

1. Romero M.D, Gomez J.M, Sanz A.G. Chem Eng Trans 2011;24:37-42.

2. Yadav G.D, M.S Mujeebur S. Rahnuman, Clean Technol Environ Policy, Springer-Verlag. 2003.

3. Jansri S, Prateerpchaikul G, Ratanawilai S.B. Acidcatalyzed esterification: a technique for reducing high free fatty acid in mixed crude palm oil, Kasetsart $J$ Nat Sci 2007;41:555-60.

4. Borer L.L. Experiments with aspirin. J Chem Edu 2000;77:354-5.

5. Rodriguez A, Nomen M, Spur B.W. A selective method for the preparation of aliphatic methyl esters in the presence of aromatic carboxylic acids. Tetrahed Lett 1998;39:8563-6.

6. Peng Y, Song G. Heteropoly acid catalyzed synthesis of aspirin. J Chem Edu 2000;5:144-58.

7. Furlan R.L.E, Mata E.G, Mascaretti O.A. Butylstannonic Acid Catalyzed Transesterification of Carboxylic Esters. Tetrahed Lett 1998;2257-60.

8. M. Shamshuddin, N. Nagaraju. Vapour phase synthesis of salol over solid acids via transesterificatio. J Chem Sci 2010;122;193-201.

9. Sawant D.P, Vinu A, Mirajkar S.P, Lefebvre F, Ariga K, Anandan S et al, J Mol Catal A: Chem 2007;271(1-2):4656.

10. E.O Akbay, M. R. Altıkka. Appl Catal A: Gen 2011;396(1-2):14-9.

11. R Teo H. T., Saha B. J Catal 2004;228(1);174-82.

12. Pizzio L, Vázquez, Cáceres C, Blanco M. Sci Catal 2000;130:953-8.
13. Pizzio L, P. Vázque P z, Cáceres C, Blanco M. Catal Lett 2001;77(4):233-9.

14. C. Khatri, A. Rani. Synthesis of a nano-crystalline solid acid catalyst from fly ash and its catalytic performance. Fuel 2008;87:2886-92.

15. Jain D, Khatri C, Rani A. Synthesis and characterization of novel solid base catalyst from fly ash. Fuel 2011;90:20838.

16. Kumar R, Kumar S, Mehrotra SP. '’Towards sustainable solutions for fly ash through mechanical activation.', Resour Conserv Recyc 2007;52:157-79.

17. Kumar S, Kumar R. The University of Wisconsin Milwaukee Centre for by-products Utilisation, Second Int Conf Sustainable Construction Mater Technol 2010; June 28- June 30.

18. Blanco F, Garcia MP, Ayala J. Variationin fly ash properties with milling and acid leaching. Fuel 2005;84:8996.

19. Bada SO, Potgieter-Vermaak S. J Prac Technol 2008;12:37-48.

20. Benezet J.C, Adamiec P, A Benhassaine. Particuol 2008;6;85-92.

21. Blanco F, Garcia M.P, Ayala J, Mayoral G, Garcia MA. The effect of mechanically and chemically activated fly ashes on mortar properties. Fuel 2006;85:2018-26.

22. Khatri C, Jain D, Rani A. Fly ash-supported cerium triflate as an active recyclable solid acid catalyst for Friedel-Crafts acylation reaction. Fuel 2010;89:3853-9.

23. B. Samah, H. Mukhtar, S. M. Shaharun. Int J Chem Environ Eng 2012;3(3):192-200.

24. E. P. Parry. An Infrared Study of Pyridi,ne Adsorbed on Acidic Solids. Characterization of Surface Acidity. J Cata 1963;2:371-9.

25. Du Y, Du X, George M.S. Mechanism of PyridineCatalyzed SiO2 Atomic Layer Deposition Studied by Fourier Transform Infrared Spectroscopy. J Phys Chem C 2007;111:219-26.

26. Kutchko B.G, Kim A.G.' Fly ash characterization by SEM-EDS”. Fuel 2006;85:2537-44.

How to cite this article: Bhatia A, Sharma S. Solid acid catalyst for isobutyl propionate production from solid waste. Int J Pharm Chem Anal 2019;6(3):63-8. 